\title{
Impact of hormone replacement therapy on the histologic subtype of breast cancer
}

\author{
Rosanna A. Zanetti-Dällenbach • Elke M. Krause • \\ Olav Lapaire · Uwe Gueth · Wolfgang Holzgreve • \\ Edward Wight
}

Received: 28 November 2007 / Accepted: 21 February 2008 / Published online: 12 March 2008

(C) Springer-Verlag 2008

\begin{abstract}
Objective Postmenopausal hormone replacement therapy (HRT) is associated with an increase in breast cancer risk, which correlates to the duration of HRT use. We wanted to investigate a possible association between HRT use and the risk of a histologic subtype of breast cancer.

Patients and methods From 1995 until 2004, 497 cases of primary ductal, lobular or ductulolobular breast cancer in postmenopausal women were diagnosed at the Department of Gynecology and Obstetrics, University Hospital Basel, Switzerland. The data was derived from patient's records. HRT ever use was defined as HRT use for $\geq 6$ months.

Results Of the 99 cases of lobular cancer $72.7 \%$ were invasive lobular cancers, $21.2 \%$ were invasive ductulolobular cancers and $6.1 \%$ were lobular cancers in situ. Of the 398 cases of ductal cancer, $90.5 \%$ were invasive ductal cancers and $9.5 \%$ were ductal cancers in situ. Totally 144 women were HRT ever users, and 341 women were HRT never users. HRT status could not be defined in 12 women. HRT ever use was associated with an increased risk for lobular cancer (OR 1.67; 95\% CI 1.02-2.73). Also, menopause due to bilateral oophorectomy was associated with an increased risk for lobular cancer (OR 2.42; 95\% CI 1.06-5.54).

Conclusions There is evidence that HRT as well as menopause due to bilateral oophorectomy may be associated
\end{abstract}

\footnotetext{
R. A. Zanetti-Dällenbach $(\bowtie) \cdot$ O. Lapaire · U. Gueth ·

W. Holzgreve $\cdot$ E. Wight

Department of Gynecology and Obstetrics,

University Hospital Basel, Spitalstrasse 21,

4031 Basel, Switzerland

e-mail: rzanetti@uhbs.ch

E. M. Krause

Department of Gynecology and Obstetrics,

Inselspital, Bern, Switzerland
}

with an increased risk for lobular cancer. This association is of major clinical relevance, since lobular breast cancer is more difficult to diagnose clinically and radiologically than ductal breast cancer.

Keywords Breast cancer $\cdot$ Histologic subtype $\cdot$ Hormone replacement therapy (HRT)

\section{Introduction}

Hormone replacement therapy (HRT) [51] is being used to treat menopausal symptoms caused by the falling levels of circulating ovarian hormones. Postmenopausal HRT is associated with an increased breast cancer risk that rises with the duration of HRT use [1, 4, 5, 16, 33, 45, 50], but dissipates after its discontinuation [1, 4, 13, 16, 33]. Breast cancer risk is no longer elevated 5 years after cessation of HRT, compared to women who never used HRT [1, 4, 13, 16, 33]. Combined estrogens-progestin HRT regimens increase breast cancer risk beyond the level associated with estrogens alone [1, 4, 14, 16, 36, 38, 41, 45].

Few previous studies have investigated a possible association between HRT use and the risk of a specific histological subtype of breast cancer with inconsistent conclusions: some studies report an elevated risk for lobular breast cancer in ever users of HRT [28, 30, 31, 34, 36], while others found no such association [47].

An increase in lobular breast cancer would be of clinical relevance since lobular breast cancer is less likely to be detected by mammography [6, 20, 22, 42, 44], ultrasound $[6,10,44]$ or clinical examination $[6,10,22,25,43]$ than ductal breast cancer. Additionally, HRT use is associated with an increase in breast density, a change which further hampers the diagnosis of breast cancer [8, 39]. 
Since diagnosis of lobular breast cancer is challenging, it is important to know if we should expect a higher incidence of lobular cancer in HRT users.

We conducted this hospital based case study to evaluate the relative risk for lobular breast cancer in current and ever HRT users in our patients.

\section{Patients and methods}

From 1995 until 2004, 661 cases of primary ductal, lobular or ductulolobular breast cancer were diagnosed at the Department of Gynecology and Obstetrics, University Hospital Basel, Switzerland. All women who were premenopausal $(n=164)$ by clinical assessment at the time of diagnosis were excluded. Totally 497 cases of postmenopausal ductal $(n=398)$ or lobular/ductulolobular $(n$ =99) breast cancer were eligible for this hospital based study.

Menopause was defined as the age of the last menstruation, or the age at bilateral oophorectomy. Women with unknown age of menopause due to premenopausal hysterectomy were considered as postmenopausal if breast cancer was diagnosed after the age of 52 .

Ever HRT use was defined as transdermal or oral HRT use for $\geq 6$ months. If the patient was on HRT for $\geq 6$ months at the time of the diagnosis or ceased HRT $\leq 3$ months before the diagnosis of breast cancer she was considered a current user.

The data considered for the current analysis derived from patient records, and if missing by telephone interview $(n=37)$. We collected data on menstrual, contraceptive and reproductive history; body size, weight, family history and personal history of invasive breast cancer or pre-invasive disease, as well as smoking, alcohol consumption, and history of diabetes. We obtained detailed information about the use, beginning, cessation, duration and brand of HRT. The institute of pathology of the University Hospital Basel provided all histological diagnoses and tumor characteristics.

Both established and suggested risk factors for breast cancer were included in the analysis as potential confounding factors, such as age at diagnosis, age at first birth, age at menopause, the type of menopause (natural, induced by bilateral oophorectomy, and unknown due to premenopausal hysterectomy), body mass index and family history of breast cancer.

\section{Statistical analysis}

In case of continuous parameters, $t$ test or categorical variables, Fishers Exact Test was calculated to compare lobular against ductal cancer (Table 1).
Multiple logistic regression was performed (Table 2) to detect the influence of the parameters age at diagnosis, age at menopause, HRT, body mass index, family history as potential confounders and natural or induced menopause on the two histological subtypes of breast cancer. Odds ratios (OR) with corresponding 95\% confidence intervals are reported for all these parameters.

In the case of continuous variables, odds ratio were expressed as the ratio of the odds from the 3rd to the 1 st quartile of the corresponding distribution.

As body mass index and age at diagnosis show a skew distribution, a log transformation was applied. A $P$-value of $<0.05$ is considered as significant. All evaluations were calculated with SPSS Version 13.0.

\section{Results}

Of the 99 cases of lobular cancer $72.7 \%(n=72)$ were invasive lobular cancer, $21.2 \%(n=21)$ were invasive ductulolobular cancer and $6.1 \%(n=6)$ were lobular cancer in situ. Of the 398 cases of ductal cancer $90.5 \%(n=360)$ were invasive ductal cancer and $9.5 \%(n=38)$ were ductal cancer in situ.

In our study we had 144 cases of breast cancer in HRT ever users and 341 cases in HRT never users. Among the ever users 109 were current and 35 were past users. In 12 cases HRT use remained unknown. The type of HRT (unopposed estrogen, estrogen plus progestin, tibolone and progestin) was comparable in ductal and lobular cancers (Table 1).

A comparison of lobular and ductal breast cancer cases is presented in Table 1 with respect to patients' and tumor characteristics.

Ever HRT use was associated with a significantly increased risk for lobular cancer OR 1.67 (95\% CI 1.022.73). Surgical induced menopause due to bilateral oophorectomy was also associated with a significantly increased risk for lobular cancer OR 2.42 (95\% CI 1.06-5.54). Age at diagnosis of breast cancer, family history for breast cancer, age at menopause, and body mass index showed no significant association to any subtype of breast cancer (Table 2).

All cases were included in the primary analysis. We also performed a subanalysis of invasive carcinomas excluding all in situ carcinomas. Bilateral oophorectomy remained associated with an increased risk for lobular cancer OR 2.32 (95\% CI 1.01-5.33), whereas HRT ever use showed a trend towards an increased risk for lobular cancer OR 1.57 (95\% CI 0.94 2.63). Another subanalysis was performed by excluding all women who had undergone premenopausal hysterectomy without bilateral oophorectomy. Bilateral oophorectomy showed an increased risk for lobular cancer OR 2.49 (95\% CI 1.06-5.86), whereas HRT ever use showed no increased risk for lobular cancer OR 1.28 (95\% CI 0.27-2.27). 
Table 1 Patients' and tumor characteristics, and characteristics of menopause and hormone replacement therapy

\begin{tabular}{|c|c|c|c|c|c|}
\hline & \multicolumn{2}{|c|}{ Ductal cancer $(n=398)$} & \multicolumn{2}{|c|}{ Lobular cancer $(n=99)$} & \multirow[t]{2}{*}{$P$} \\
\hline & Mean $(n)$ & Min-max $(\%)$ & Mean $(n)$ & $\operatorname{Min}-\max (\%)$ & \\
\hline \multicolumn{6}{|l|}{ Patients characteristics } \\
\hline Age at diagnosis of breast cancer (in years) & 66.98 & $45-96$ & 66.58 & $42-94$ & ns \\
\hline Age at menarche (in years) & 13.56 & $9-20$ & 13.46 & $10-19$ & ns \\
\hline Age at menopause (in years) & 49.99 & $34-63$ & 50.33 & $33-63$ & ns \\
\hline Age at first birth (in years) & 25.65 & $17-47$ & 26.21 & $17-46$ & ns \\
\hline Parity & 1.62 & $0-6$ & 1.71 & $0-5$ & ns \\
\hline Family history of breast cancer & & & & & ns \\
\hline Positive & 87 & 21.9 & 31 & 31.3 & \\
\hline Negative & 300 & 75.3 & 65 & 65.7 & \\
\hline Unknown & 11 & 2.8 & 3 & 3.0 & \\
\hline Body mass index & 25.89 & $16-42$ & 25.83 & $19-40$ & ns \\
\hline Alcohol consumption & & & & & ns \\
\hline Never & 163 & 41.0 & 43 & 43.5 & \\
\hline Regular & 227 & 57.0 & 53 & 53.5 & \\
\hline Unknown & 8 & 2.0 & 3 & 3.0 & \\
\hline Smoking & & & & & ns \\
\hline Never & 315 & 79.1 & 71 & 71.7 & \\
\hline Past or current smokers & 77 & 19.4 & 25 & 25.3 & \\
\hline Unknown & 6 & 1.5 & 3 & 3.0 & \\
\hline History of diabetes & 42 & 10.6 & 9 & 9.1 & ns \\
\hline \multicolumn{6}{|l|}{ Tumor characteristics } \\
\hline Tumor size & & & & & 0.047 \\
\hline In situ & 38 & 9.5 & 6 & 6.1 & \\
\hline pT1 & 183 & 46.0 & 37 & 37.4 & \\
\hline pT2 & 120 & 30.2 & 36 & 36.4 & \\
\hline pT3 & 19 & 4.8 & 12 & 12.1 & \\
\hline pT4 & 38 & 9.5 & 8 & 8.0 & \\
\hline Lymph nodes & & & & & ns \\
\hline Negative & 246 & 61.8 & 52 & 52.6 & \\
\hline Positive & 143 & 36.0 & 44 & 44.4 & \\
\hline $\mathrm{Nx}$ & 9 & 2.2 & 3 & 3.0 & \\
\hline Distant disease & & & & & ns \\
\hline M0 & 371 & 93.2 & 90 & 90.9 & \\
\hline M1 & 23 & 5.8 & 9 & 9.1 & \\
\hline Mx & 4 & 1.0 & 0 & 0.0 & \\
\hline Grading & & & & & 0.005 \\
\hline 1 & 86 & 21.6 & 8 & 8.1 & \\
\hline 2 & 194 & 48.7 & 59 & 59.6 & \\
\hline 3 & 118 & 29.7 & 32 & 32.3 & \\
\hline Estrogens receptor & & & & & ns \\
\hline Positive & 315 & 79.1 & 84 & 84.9 & \\
\hline Negative & 77 & 19.4 & 13 & 13.1 & \\
\hline Unknown & 6 & 1.5 & 2 & 2.0 & \\
\hline Progesterone receptor & & & & & ns \\
\hline Positive & 248 & 62.3 & 68 & 68.7 & \\
\hline Negative & 144 & 36.2 & 29 & 29.3 & \\
\hline Unknown & 6 & 1.5 & 2 & 2.0 & \\
\hline
\end{tabular}


Table 1 continued

\begin{tabular}{|c|c|c|c|c|c|}
\hline & \multicolumn{2}{|c|}{ Ductal cancer $(n=398)$} & \multicolumn{2}{|c|}{ Lobular cancer $(n=99)$} & \multirow[t]{2}{*}{$P$} \\
\hline & Mean $(n)$ & Min-max $(\%)$ & Mean $(n)$ & Min-max $(\%)$ & \\
\hline \multicolumn{6}{|l|}{ Menopause and hormone replacement therapy } \\
\hline Menopause & & & & & ns \\
\hline Natural & 286 & 71.9 & 68 & 68.7 & \\
\hline $\begin{array}{l}\text { History of premenopausal hysterectomy } \\
\text { without bilateral oophorectomy }\end{array}$ & 92 & 23.1 & 21 & 21.2 & \\
\hline $\begin{array}{l}\text { Menopause induced by } \\
\text { bilateral oophorectomy }\end{array}$ & 20 & 5.0 & 10 & 10.1 & \\
\hline Hormone replacement therapy & & & & & 0.026 \\
\hline Never user & 282 & 70.9 & 59 & 59.6 & \\
\hline Ever user & 106 & 26.6 & 38 & 38.4 & \\
\hline Unknown & 10 & 2.5 & 2 & 2.0 & \\
\hline Type of replacement therapy & & & & & ns \\
\hline Estrogens plus progestin & 50 & 47.2 & 20 & 52.6 & \\
\hline Estrogens monotherapy & 54 & 51.0 & 15 & 39.5 & \\
\hline Tibolon & 1 & 0.9 & 2 & 5.3 & \\
\hline Progestin & 1 & 0.9 & 1 & 2.6 & \\
\hline
\end{tabular}

Table 2 Multivariate analysis for factors influencing the histological subtype of breast cancer

\begin{tabular}{lllll}
\hline & $\begin{array}{l}\text { Ductal } \\
\text { cancer }\end{array}$ & $\begin{array}{l}\text { Lobular } \\
\text { cancer }\end{array}$ & OR & $95 \%$ CI \\
\hline $\begin{array}{l}\text { Age at diagnosis of } \\
\text { breast cancer }\end{array}$ & 398 & 99 & 1.03 & $0.70-1.52$ \\
$\begin{array}{c}\text { Family history for } \\
\text { breast cancer }\end{array}$ & 387 & 96 & 1.5 & $0.95-2.56$ \\
$\begin{array}{l}\text { Age at menopause } \\
\text { b }\end{array}$ & 398 & 99 & 1.19 & $0.88-1.62$ \\
$\begin{array}{l}\text { Body mass index } \\
\text { Hormone replacement } \\
\text { therapy }\end{array}$ & 398 & 99 & 1.03 & $0.75-1.41$ \\
Type of menopause $^{\mathrm{e}}$ & 398 & 97 & 1.67 & $1.02-2.73$ \\
\hline
\end{tabular}

${ }^{\text {a }}$ First quartile $=58$, third quartile $=65$

${ }^{\mathrm{b}}$ First quartile $=47$, third quartile $=53$

${ }^{c}$ First quartile $=23$, third quartile $=28.6$

Reference groups

${ }^{d}$ HRT ever use, HRT never use

e Natural menopause (women with a history of premenopausal hysterectomy without oophorectomy included), menopause induced by premenopausal bilateral oophorectomy

\section{Discussion}

Breast cancer incidence seems to be stable or declining since 2003 [21, 35]. Up to 2003, however, breast cancer incidence had been rising in Western countries [24, 25], and there is evidence that this was more pronounced in lobular breast cancer than in ductal breast cancer.
Li et al. [24] reported a plateau in the incidence of ductal breast cancer, but an increase in the incidence of lobular breast cancer between 1987 and 1995 in the US. Two studies from Switzerland [23, 48] did not report a plateau, but an increased incidence rate in ductal $(0.9-1.2 \%$ per year) as well as lobular (10-14\% per year) breast cancer. The increase, however, was more substantial in lobular breast cancer. Furthermore, there seem to exist sharp differences in the incidence as well as in the histological subtyping of breast cancer between different European populations [49]. The rise of HRT use of 38-50\% between 1987 and 1992 suggests an association between HRT use and increasing incidence of lobular breast cancer [5, 9, 18, 24].

Our data show an increased risk for lobular cancer in HRT ever users OR 1.67 (95\% CI 1.02-2.73) and in women after bilateral oophorectomy OR 2.42 (95\% CI 1.06-5.54).

In the primary analysis, where all cases were included, HRT ever use OR 1.67 (95\% CI 1.02-2.73) showed a significant association with lobular cancer. Excluding all women with in situ carcinomas, a trend towards an increased risk for lobular cancer in HRT ever users OR 1.57 (95\% CI 0.94-2.63) was seen. However, by excluding women who underwent premenopausal hysterectomy without bilateral oophorectomy, HRT ever users no longer showed an increased risk for lobular breast cancer OR 1.28 (CI 0.27-2.27). This might be explained by the fact that these women were usually estrogen HRT ever users.

Other studies are in agreement with our data $[28,31,34$, 36, 49]. Li et al. [24] also included in situ cancers in their analysis and reported an increased risk for lobular cancer 
(OR 2.1; 95\% CI 1.0-4.6), but not for ductal cancer. Likewise, the data of Newcomer et al. [34] showed an increased risk of lobular breast cancer (OR 1.5; 95\% CI 1.1-2.1) in HRT ever users (estrogen alone and estrogen plus progestin), but not for ductal cancer.

Other authors reported an increased risk for ductal as well as lobular breast cancer, which was more pronounced for the latter [13, 17, 26, 33, 37, 45]. The pronounced risk of lobular breast cancer was seen after combined HRT (estrogen plus progestin) [17, 26, 33] and estrogen alone HRT, as well as after combined HRT in other studies [13, $37,45]$. In contrast, other groups did not find evidence that the effect of HRT was restricted to or more pronounced in lobular cancer [47].

While our data show a significant influence of surgical menopause by bilateral oophrectomy on the incidence of lobular breast cancer [OR 2.42 (95\% CI 1.06-5.54)], only a statistical trend was seen in the work of others [27]. Excluding all women with in situ carcinomas OR 2.32 (95\% CI 1.01-5.33), and all women who underwent premenopausal hysterectomy without bilateral oophorectomy OR 2.49 (CI 1.06-5.86) bilateral oophorectomy remained associated with an increased risk for lobular cancer. HRT is frequently prescribed to reduce menopausal symptoms caused by premenopausal bilateral oophrectomy. Therefore, these women take HRT earlier in life, and for a longer period.

Substantial methodological differences between the studies analyzing the effects of HRT and certain subtypes of breast cancer make a comparison of the data very difficult. Some authors restricted the age of women included in the studies to 65 years $[17,28,31]$, whereas we and others include also elderly women [13, 26, 34, 37]. Some studies compare invasive ductal to lobular cancers [34] while others compare lobular to nonlobular cancers [13] or ductal to lobular and to tubular cancers [37]. As in the presented data lobular and ductulolobular cancers are compared to ductal cancers [17] and in situ cancers are included in the analysis [28]. In agreement to our study some authors define HRT use if HRT was used for $\geq 6$ months [13, 28], while others define it as $\geq 3$ months [34]. Many studies do not define HRT use at all.

A shortcoming of our study is the relatively small number of breast cancer cases in HRT ever users and the small number of lobular cancers. The charts did not contain structured questionnaires, and missing data were obtained by telephone interview.

In spite of the relatively small numbers of breast cancer cases in our cohort study, the presented data add to the growing evidence that HRT might be associated to lobular breast cancer. This association is of major clinical relevance, since lobular breast cancer is more difficult to diagnose than ductal breast cancer.

Invasive lobular breast cancers are distinguished histologicaly from infiltrating ductal carcinomas by their diffusive infiltrative pattern that does not destroy the anatomic structures. They often fail to form distinct masses due to the lack of a desmoplastic reaction which prevents the lesions from being clinically and radiologically detected.

As a result, the sensitivity of a physical examination, including mammography and ultrasound to detect lobular breast cancer is lower than for the more common ductal breast cancer [2, 10, 22, 43, 44]. This is also shown by our data since lobular breast cancer tends to be larger in size than ductal breast cancer at diagnosis.

Subtle changes that may mimic normal breast parenchyma, including opacity similar to that of normal fibroglandular tissue, as well as the common lack of suspicious microcalcifications are reasons for the high rate of up to $19 \%$ false-negative mammographic diagnosis $[6,20,22$, $39,42,44,52]$. In up to $8 \%$, mammograms may even be completely normal in lobular breast cancer [20, 42, 44].

While ultrasound seems to be more sensitive in detecting lobular breast cancer than mammography, a false negative rate of $12.3 \%$ has been reported. [6, 10, 20, 42, 44].

HRT increases mammographic breast density and decreases the sensitivity and specificity of mammography $[3,8,12,15,19,29,39]$ further leaving breast cancer undetected [3, 6-8, 11, 12, 15, 32, 39, 40, 46].

Equivocal clinical, mammographic or sonographic findings in the breasts of women with a history of menopause induced by oophorectomy, or in past or current HRT users should lead to further investigations to exclude lobular breast cancer.

Our data show an increased risk for lobular breast cancer in ever HRT users and in patients with a history of menopause induced by bilateral oophorectomy. This is relevant since lobular breast cancer might pose a diagnostic challenge.

Conflict of interest No conflicts of interest to declare.

\section{References}

1. Anonymous (1997) Breast cancer and hormone replacement therapy: collaborative reanalysis of data from 51 epidemiological studies of 52,705 women with breast cancer and 108,411 women without breast cancer. Collaborative group on hormonal factors in breast cancer. Lancet 350:1047-1059

2. Arpino G, Bardou VJ, Clark GM, Elledge RM (2004) Infiltrating lobular carcinoma of the breast: tumor characteristics and clinical outcome. Breast Cancer Res 6:R149-R156

3. Banks E (2001) Hormone replacement therapy and the sensitivity and specificity of breast cancer screening: a review. J Med Screen 8:29-34

4. Beral V (2003) Breast cancer and hormone-replacement therapy in the Million Women Study. Lancet 362:419-427

5. Beral V, Banks E, Reeves G (2002) Evidence from randomised trials on the long-term effects of hormone replacement therapy. Lancet 360:942-944

6. Berg WA, Gutierrez L, NessAiver MS, Carter WB, Bhargavan M, Lewis RS, Ioffe OB (2004) Diagnostic accuracy of mammography, 
clinical examination, US, and MR imaging in preoperative assessment of breast cancer. Radiology 233:830-849

7. Boyd NF, Byng JW, Jong RA, Fishell EK, Little LE, Miller AB, Lockwood GA, Tritchler DL, Yaffe MJ (1995) Quantitative classification of mammographic densities and breast cancer risk: results from the Canadian National Breast Screening Study. J Natl Cancer Inst 87:670-675

8. Boyd NF, Martin LJ, Li Q, Sun L, Chiarelli AM, Hislop G, Yaffe MJ, Minkin S (2006) Mammographic density as a surrogate marker for the effects of hormone therapy on risk of breast cancer. Cancer Epidemiol Biomarkers Prev 15:961-966

9. Brett KM, Madans JH (1997) Use of postmenopausal hormone replacement therapy: estimates from a nationally representative cohort study. Am J Epidemiol 145:536-545

10. Butler RS, Venta LA, Wiley EL, Ellis RL, Dempsey PJ, Rubin E (1999) Sonographic evaluation of infiltrating lobular carcinoma. AJR Am J Roentgenol 172:325-330

11. Byrne C, Schairer C, Brinton LA, Wolfe J, Parekh N, Salane M, Carter C, Hoover R (2001) Effects of mammographic density and benign breast disease on breast cancer risk (United States). Cancer Causes Control 12:103-110

12. Carney PA, Miglioretti DL, Yankaskas BC, Kerlikowske K, Rosenberg R, Rutter CM, Geller BM, Abraham LA, Taplin SH, Dignan M, Cutter G, Ballard-Barbash R (2003) Individual and combined effects of age, breast density, and hormone replacement therapy use on the accuracy of screening mammography. Ann Intern Med 138:168-175

13. Chen CL, Weiss NS, Newcomb P, Barlow W, White E (2002) Hormone replacement therapy in relation to breast cancer. Jama 287:734-741

14. Chlebowski RT, Hendrix SL, Langer RD, Stefanick ML, Gass M, Lane D, Rodabough RJ, Gilligan MA, Cyr MG, Thomson CA, Khandekar J, Petrovitch H, McTiernan A (2003) Influence of estrogen plus progestin on breast cancer and mammography in healthy postmenopausal women: the Women's Health Initiative Randomized Trial. Jama 289:3243-3253

15. Clemons M, Goss P (2001) Estrogen and the risk of breast cancer. N Engl J Med 344:276-285

16. Colditz GA, Hankinson SE, Hunter DJ, Willett WC, Manson JE, Stampfer MJ, Hennekens C, Rosner B, Speizer FE (1995) The use of estrogens and progestins and the risk of breast cancer in postmenopausal women. N Engl J Med 332:1589-1593

17. Daling JR, Malone KE, Doody DR, Voigt LF, Bernstein L, Coates RJ, Marchbanks PA, Norman SA, Weiss LK, Ursin G, Berlin JA, Burkman RT, Deapen D, Folger SG, McDonald JA, Simon MS, Strom BL, Wingo PA, Spirtas R (2002) Relation of regimens of combined hormone replacement therapy to lobular, ductal, and other histologic types of breast carcinoma. Cancer 95:2455-2464

18. Glass AG, Lacey JV Jr., Carreon JD, Hoover RN (2007) Breast cancer incidence, 1980-2006: combined roles of menopausal hormone therapy, screening mammography, and estrogen receptor status. J Natl Cancer Inst 99:1152-1161

19. Greendale GA, Reboussin BA, Sie A, Singh HR, Olson LK, Gatewood O, Bassett LW, Wasilauskas C, Bush T, Barrett-Connor E (1999) Effects of estrogen and estrogen-progestin on mammographic parenchymal density. Postmenopausal Estrogen/Progestin Interventions (PEPI) Investigators. Ann Intern Med 130:262-269

20. Helvie MA, Paramagul C, Oberman HA, Adler DD (1993) Invasive lobular carcinoma. Imaging features and clinical detection. Invest Radiol 28:202-207

21. Kerlikowske K, Miglioretti DL, Buist DS, Walker R, Carney PA (2007) Declines in invasive breast cancer and use of postmenopausal hormone therapy in a screening mammography population. J Natl Cancer Inst 99:1335-1339
22. Krecke KN, Gisvold JJ (1993) Invasive lobular carcinoma of the breast: mammographic findings and extent of disease at diagnosis in 184 patients. AJR Am J Roentgenol 161:957-960

23. Levi F, Te VC, Randimbison L, La Vecchia C (2003) Increase in lobular breast cancer incidence in Switzerland. Int $\mathrm{J}$ Cancer 107:164-165, author reply 166

24. Li CI, Anderson BO, Daling JR, Moe RE (2002) Changing incidence of lobular carcinoma in situ of the breast. Breast Cancer Res Treat 75:259-268

25. Li CI, Anderson BO, Daling JR, Moe RE (2003) Trends in incidence rates of invasive lobular and ductal breast carcinoma. Jama 289:1421-1424

26. Li CI, Malone KE, Porter PL, Weiss NS, Tang MT, Cushing-Haugen KL, Daling JR (2003) Relationship between long durations and different regimens of hormone therapy and risk of breast cancer. Jama 289:3254-3263

27. Li CI, Malone KE, Porter PL, Weiss NS, Tang MT, Daling JR (2003) Reproductive and anthropometric factors in relation to the risk of lobular and ductal breast carcinoma among women 65-79 years of age. Int J Cancer 107:647-651

28. Li CI, Weiss NS, Stanford JL, Daling JR (2000) Hormone replacement therapy in relation to risk of lobular and ductal breast carcinoma in middle-aged women. Cancer 88:2570-2577

29. Lundstrom E, Christow A, Kersemaekers W, Svane G, Azavedo E, Soderqvist G, Mol-Arts M, Barkfeldt J, von Schoultz B (2002) Effects of tibolone and continuous combined hormone replacement therapy on mammographic breast density. Am J Obstet Gynecol 186:717-722

30. Lyytinen H, Pukkala E, Ylikorkala O (2006) Breast cancer risk in postmenopausal women using estrogen-only therapy. Obstet Gynecol 108:1354-1360

31. Manjer J, Malina J, Berglund G, Bondeson L, Garne JP, Janzon L (2001) Increased incidence of small and well-differentiated breast tumours in post-menopausal women following hormone-replacement therapy. Int J Cancer 92:919-922

32. Nagao Y, Kawaguchi Y, Sugiyama Y, Saji S, Kashiki Y (2003) Relationship between mammographic density and the risk of breast cancer in Japanese women: a case-control study. Breast Cancer 10:228-233

33. Newcomb PA, Titus-Ernstoff L, Egan KM, Trentham-Dietz A, Baron JA, Storer BE, Willett WC, Stampfer MJ (2002) Postmenopausal estrogen and progestin use in relation to breast cancer risk. Cancer Epidemiol Biomarkers Prev 11:593-600

34. Newcomer LM, Newcomb PA, Potter JD, Yasui Y, Trentham-Dietz A, Storer BE, Longnecker MP, Baron JA, Daling JR (2003) Postmenopausal hormone therapy and risk of breast cancer by histologic type (United States). Cancer Causes Control 14:225-233

35. Ravdin PM, Cronin KA, Howlader N, Berg CD, Chlebowski RT, Feuer EJ, Edwards BK, Berry DA (2007) The decrease in breastcancer incidence in 2003 in the United States. N Engl J Med 356:1670-1674

36. Reeves GK, Beral V, Green J, Gathani T, Bull D (2006) Hormonal therapy for menopause and breast-cancer risk by histological type: a cohort study and meta-analysis. Lancet Oncol 7:910-918

37. Rosenberg LU, Magnusson C, Lindstrom E, Wedren S, Hall P, Dickman PW (2006) Menopausal hormone therapy and other breast cancer risk factors in relation to the risk of different histological subtypes of breast cancer: a case-control study. Breast Cancer Res 8:R11

38. Rossouw JE, Anderson GL, Prentice RL, LaCroix AZ, Kooperberg C, Stefanick ML, Jackson RD, Beresford SA, Howard BV, Johnson KC, Kotchen JM, Ockene J (2002) Risks and benefits of estrogen plus progestin in healthy postmenopausal women: principal results From the Women's Health Initiative randomized controlled trial. Jama 288:321-333 
39. Sala E, Warren R, McCann J, Duffy S, Luben R, Day N (2000) High-risk mammographic parenchymal patterns, hormone replacement therapy and other risk factors: a case-control study. Int $\mathbf{J}$ Epidemiol 29:629-636

40. Sala E, Warren R, McCann J, Duffy S, Luben R, Day N (2001) Mammographic parenchymal patterns and breast cancer natural history-a case-control study. Acta Oncol 40:461-465

41. Schairer C, Lubin J, Troisi R, Sturgeon S, Brinton L, Hoover R (2000) Menopausal estrogen and estrogen-progestin replacement therapy and breast cancer risk. Jama 283:485-491

42. Selinko VL, Middleton LP, Dempsey PJ (2004) Role of sonography in diagnosing and staging invasive lobular carcinoma. J Clin Ultrasound 32:323-332

43. Silverstein MJ, Lewinsky BS, Waisman JR, Gierson ED, Colburn WJ, Senofsky GM, Gamagami P (1994) Infiltrating lobular carcinoma. Is it different from infiltrating duct carcinoma? Cancer 73:1673-1677

44. Skaane P, Skjorten F (1999) Ultrasonographic evaluation of invasive lobular carcinoma. Acta Radiol 40:369-375

45. Tjonneland A, Christensen J, Thomsen BL, Olsen A, Overvad K, Ewertz M, Mellemkjaer L (2004) Hormone replacement therapy in relation to breast carcinoma incidence rate ratios: a prospective Danish cohort study. Cancer 100:2328-2337

46. Ursin G, Ma H, Wu AH, Bernstein L, Salane M, Parisky YR, Astrahan M, Siozon CC, Pike MC (2003) Mammographic density and breast cancer in three ethnic groups. Cancer Epidemiol Biomarkers Prev 12:332-338
47. Ursin G, Tseng CC, Paganini-Hill A, Enger S, Wan PC, Formenti S, Pike MC, Ross RK (2002) Does menopausal hormone replacement therapy interact with known factors to increase risk of breast cancer? J Clin Oncol 20:699-706

48. Verkooijen HM, Fioretta G, Vlastos G, Morabia A, Schubert H, Sappino AP, Pelte MF, Schafer P, Kurtz J, Bouchardy C (2003) Important increase of invasive lobular breast cancer incidence in Geneva, Switzerland. Int J Cancer 104:778-781

49. Verkooijen HM, Koot VC, Fioretta G, van der Heiden M, Schipper ME, Rapiti E, Peeters PH, Peterse JL, Bouchardy C (2007) Hormone replacement therapy, mammography screening and changing age-specific incidence rates of breast cancer: an ecological study comparing two European populations. Breast Cancer Res Treat 107(3):389-395. Epub 13, March 2007

50. Weiss LK, Burkman RT, Cushing-Haugen KL, Voigt LF, Simon MS, Daling JR, Norman SA, Bernstein L, Ursin G, Marchbanks PA, Strom BL, Berlin JA, Weber AL, Doody DR, Wingo PA, McDonald JA, Malone KE, Folger SG, Spirtas R (2002) Hormone replacement therapy regimens and breast cancer risk(1). Obstet Gynecol 100:1148-1158

51. Wohlfahrt J, Mouridsen H, Andersen PK, Melbye M (1999) Reproductive risk factors for breast cancer by receptor status, histology, laterality and location. Int J Cancer 81:49-55

52. Yeatman TJ, Cantor AB, Smith TJ, Smith SK, Reintgen DS, Miller MS, Ku NN, Baekey PA, Cox CE (1995) Tumor biology of infiltrating lobular carcinoma. Implications for management. Ann Surg 222:549-559, discussion 559-561 